\title{
Adenosquamous Carcinoma of the Uterine Cervix - Impact of Histology on Clinical Management
}

\author{
Angel Yordanov' \\ Stoyan Kostov ${ }^{2}$ \\ Stanislav Slavchev ${ }^{2}$ \\ Strahil Strashilov $\mathbb{1 D}^{3}$ \\ Assia Konsoulova ${ }^{4}$ \\ Jean Calleja-Agius ${ }^{5}$ \\ Riccardo Di Fiore $\mathbb{D I D}^{5,6}$ \\ Sherif Suleiman $\mathbb{D}^{5}$ \\ Paul Kubelac ${ }^{7,8}$ \\ Catalin Vlad ${ }^{8,9}$ \\ Patriciu Achimas-Cadariu ${ }^{8,9}$ \\ Mariela Vasileva-Slaveva ${ }^{10,1}$ \\ 'Department of Gynecologic Oncology, \\ Medical University Pleven, Pleven, 5800, \\ Bulgaria; ${ }^{2}$ Department of Gynecology, \\ Medical University Varna "Prof. Dr. Paraskev \\ Stoyanov", Varna, 9002, Bulgaria; \\ ${ }^{3}$ Department of plastic and reconstructive \\ surgery, MU-Pleven, Pleven, 5800, Bulgaria; \\ ${ }^{4}$ Department of Medical Oncology, \\ Complex Oncological Center Burgas, \\ Burgas, 8000, Bulgaria; ${ }^{5}$ Department of \\ Anatomy, Faculty of Medicine and Surgery, \\ University of Malta, Msida, MSD 2080, \\ Malta; ${ }^{6}$ Center for Biotechnology, Sbarro \\ Institute for Cancer Research and Molecular \\ Medicine, College of Science and \\ Technology, Temple University, Philadelphia, \\ PA, 19122, USA; ${ }^{7}$ Department of Medical \\ Oncology, The Oncology Institute "Prof. \\ Dr. Ion Chiricuta", Cluj-Napoca, 4000I5, \\ Romania; ${ }^{8}$ Department of Oncology, "Iuliu \\ Hatieganu" University of Medicine and \\ Pharmacy, Cluj-Napoca, 4000 I2, Romania; \\ ${ }^{9}$ Department of Surgery, The Oncology \\ Institute "Prof. Dr. Ion Chiricuta", Cluj \\ Napoca, 400015, Romania; ${ }^{10}$ Department of \\ surgery, University Hospital Acibadem City \\ Clinic, Sofia, Bulgaria; "Women for \\ Oncology - Bulgaria Society, Bulgaria
}

Correspondence: Angel Yordanov

Bul Georgi Kochev 8A, Pleven, 5800,

Bulgaria

Tel +359-98-8767-1520

Email angel.jordanov@gmail.com
Introduction: Historically, the incidence rate of cervical cancer (CC) in Eastern Europe and particularly in Bulgaria has constantly been higher than that in the other European countries. Adenosquamous carcinoma (ASC) is a rare histological subtype of CC with incidence rate of less than 6 per 100,000. We aimed to analyze the epidemiology and prognosis of all Bulgarian patients with ASC, registered at the Bulgarian National Cancer Registry (BNCR), and to compare patients' characteristics and outcomes with those of patients, treated at a large specialized institution - the Department of Gynecologic Oncology, University Hospital in Pleven, Bulgaria.

Materials and Methods: This is a retrospective study of all cases of ASC, registered at the BNCR for a 10-year period of time. The Kaplan-Meier analysis with Log rank test was used to estimate the significant differences.

Results: The incidence rate of ASC was calculated as $3.2 \%$ of all CC registered in BNCR and $4.97 \%$ of all stage I patients, treated in our department. The 5 -year overall survival (OS) rate of all patients with ASC tumors from the registry was 50.5\%. A total of $171(48.4 \%)$ of the patients had T1 tumors and a 5-year OS of 67.1\%. Lymph node status was a significant prognostic factor for OS $(\mathrm{p}=0.001)$. Thirty-one patients with T1 tumors and ASC histology were treated in our department for the same period of time. Lymph node metastases were found in 10 of them (32.2\%). The 5-year observed OS in ASC group was $74.19 \%$.

Conclusion: The histological subtype of cancer of the uterine cervix has an impact on prognosis and should not be simply considered as a descriptive characteristic but a poor prognostic feature and should be an integral part of the decision-making in clinical management of patients.

Keywords: adenosquamous cervical carcinoma, incidence rate, clinical features, survival rate, prognosis

\section{Introduction}

Cervical carcinoma (CC) is both the fourth most common malignancy and cause of cancer-related death in women worldwide. ${ }^{1}$ The world age-standardized incidence rate (ASIR) of CC is 13.1 per 100,000, but there are big disparities according to the geographic region and the countries' Human Development Index. ${ }^{2}$ Historically, the incidence rate of $\mathrm{CC}$ in Eastern Europe has constantly been higher than that in the other European countries. ${ }^{3}$ In Bulgaria for 2008 the ASIR is 21.9 per 100,000 and for 201820.3 per $100000 .^{4}$

With the introduction of national screening programs and wider HPV vaccination, it is expected that both incidence and mortality will decrease by 2030 . Still, there are examples where vaccination is not as effective as expected ${ }^{5}$ and the 
screening is not equally effective for the prevention of different histological types of $\mathrm{CC}^{6}$

Histological classification of $\mathrm{CC}$ distinguishes three major types - squamous cell carcinoma (SCC), adenocarcinoma (AC), and adenosquamous carcinoma (ASC). SCC is the most common type with $75-80 \%$ of the cases; AC and ASC together account for $15-20 \%{ }^{7}$ The prevalence of ASC varies within $3-10 \%$ of all $\mathrm{CC}^{7-10}$ and could be defined as a rare cancer (with an incidence rate of less than $6 / 100,000) .{ }^{9}$ There are specific pathological features that should be present in order to classify a tumor as an adenosquamous subtype: both malignant squamous and glandular components should be present in routine hematoxylin and eosin staining sections; use of special immunohistochemical tests is not a mandatory condition. ${ }^{11}$ ASC should also be distinguished from the large-cell nonkeratinizing squamous cell carcinoma (LCSC) and the endometrioid adenocarcinomas with squamous metaplasia in which the squamous component is benign. ${ }^{10}$

ASC was first described by Greene in $1963 .{ }^{12}$ In 2014, the World Health Organization (WHO) defined it as a malignant epithelial tumor, composed of a mixture of invasive adenocarcinoma and squamous cell carcinoma. ${ }^{13}$ Still, the diagnosis of ASC can frequently be difficult. Recent analysis of the morphology of this subtype showed that $42 \%$ of the cases, primary diagnosed as ASC, were further reclassified. ${ }^{14}$ Besides the more complicated morphology, ASCs also differ from SCCs and ACs in prognosis. ${ }^{15-18}$ In patients, undergoing surgical resection, followed by radiotherapy, ASC has shown intermediate prognosis between SCC and AC. ${ }^{19}$ Patients with a more advanced stage of ASC and AC and treated with definitive radiotherapy had worse outcomes, compared to SCC. ${ }^{20}$

We aimed to analyze the incidence rate and the prognostic factors for overall survival (OS) among patients with ASC of the uterine cervix, registered at the Bulgarian National Cancer Registry and the patients, treated at a specialized oncogynecological institution - the Department of Gynaecologic Oncology, University Hospital in Pleven, Bulgaria for a period of 10 years (2007-2016).

\section{Materials and Methods Study of Population}

This is a retrospective study of patients, diagnosed with ASC of the uterine cervix for a 10-years period of time between January 1st, 2007, and December 31st, 2016. A total of 10,994 women were diagnosed with cancer of the uterine cervix in Bulgaria and $353(3.2 \%)$ of them were registered with ASC. An ethical committee approval (number 414-КЕНИД/31.03.2016) was obtained from all patients who operated for cervical cancer at Department of Gynecologic Oncology, University Hospital—Pleven, Bulgaria for the study period. In this time period, no specific informed consent was used for patients from Medical University Pleven. All patients have signed a common informed consent in which they agree to provide their clinical and pathological data for research.

We divided patients into two groups:

- patients, registered in the Bulgarian National Cancer Registry (group 1);

- patients, treated at the Department of Gynaecologic Oncology, University Hospital in Pleven, Bulgaria (group 2).

Information and tumor characteristics of patients, treated at the Medical University Pleven (group 2), were obtained from the patients' medical records. These characteristics for the group of patients from the BNCR (group 1) were extracted from the available data from the Registry. Standard follow-up procedures for both groups 1 and 2 included clinical examinations, abdominal ultrasound, $\mathrm{X}$-ray of the chest and blood tests every 3 months during the first 2 years, every six months between third and fifth year and then annually; annual whole-body CT screening.

Ethical committee for research in science of Medical University Pleven approval (\#414-REC/31.03.2016) was obtained to perform the study.

\section{Pathologic Characteristics}

We collected data for age, tumor stage at diagnosis, tumor grade and TNM and FIGO classification. To classify and stage the tumors, the 6th edition of the TNM classification and FIGO classification 2009 was used. For group 2 patients, pathological tests were done on archival paraffinembedded tissues and the diagnoses were centrally reconfirmed based on H\&E stained slides. Characteristics of patients, registered for the study period at the BNCR, are shown on Table 1.

ASC is rarely seen before the age of 40 and after the age of 70 years. Most commonly, it is diagnosed in 1st stage and with negative lymph nodes. Still for more than $20 \%$ of patients, the status of the lymph nodes remains unknown according to data from the BNCR. 
Table I Characteristics of Patients, Registered at the BNCR

\begin{tabular}{|l|l|l|}
\hline Patients' Characteristics & N & (\%) \\
\hline Age (mean) & $54.8(26-88)$ & \\
Age <40 & 50 & 14.2 \\
$40-69$ & 246 & 69.7 \\
$>70$ & 57 & 16.1 \\
TNM Stage I & 145 & 41.1 \\
TNM Stage II & 77 & 21.8 \\
TNM Stage III & 98 & 27.8 \\
TNM Stage IV & 23 & 6.5 \\
Unkown TNM Stage & 10 & 2.8 \\
TI & 171 & 48.4 \\
T2 & 91 & 25.8 \\
T3 & 72 & 20.4 \\
T4 & 10 & 2.8 \\
Unkown T & 9 & 2.5 \\
N0 & 199 & 56.4 \\
NI & 71 & 20.1 \\
Unkown N & 83 & 23.5 \\
MI at diagnosis & 18 & 5.1 \\
GI & 5 & 1.4 \\
G2 & 117 & 33.1 \\
G3 & 91 & 25.8 \\
Unknown G & 140 & 39.7 \\
Total & 353 & 100.0 \\
\hline
\end{tabular}

For the same period of time at Medical University Pleven 31 patients have been diagnosed with ASC of the uterine cervix. All cases were centrally reviewed to reconfirm diagnosis.

\section{Statistical Analysis}

All patients were followed up until April 1st, 2020. The survival was estimated only in patients with only one cancer primary, who had survival longer than 1 month after diagnosis. Statistical analysis was performed by SPSS, version 24.0 (SPSS, Inc., Chicago, IL). The Kaplan-Meier analysis with Log rank test was used to test for significance. Comparison between the two groups of patients was performed in $\mathrm{R}$ with ggplot2 library using $t$-test to investigate the significance. The significance level of the $p$ value was set to 0.05 for a two-tailed analysis.

\section{Results}

During the 10 years of the study period, A total of 10,994 women have been diagnosed with cancer of the uterine cervix in Bulgaria and were analyzed as group 1. In total, $353(3.2 \%)$ of them had ASC. Distribution of patients, according to the year of diagnosis and the prevalence of ASC is shown in Figure 1.
In group 1, the highest incidence rate of ASC is observed in women of age 50-64. ASC is commonly diagnosed in stage I, but more than half of the cases are diagnosed in advanced stage. In most cases, ASC has intermediate G2 differentiation, it is diagnosed with T1 tumor and negative lymph nodes. From all 353 patients with ASC, 272 (77\%) were surgically treated. In total, $182(67 \%)$ of them were also treated with radiotherapy. All 31 patients with ASC from our institution underwent surgical treatment and postoperative radiotherapy.

The median follow-up time for patients in both analysis groups, still alive at the time of this analysis, was 99.6 months. The 5-years OS rate of all patients with ASC was $50.5 \%$. Among all registered cases of ASC, there were 171 $(48.4 \%) \mathrm{T} 1$ tumors, and $100(58.5 \%)$ of them have received both surgery and radiotherapy. The 5-year survival rate calculated for patients followed up for more than 5 years, was $67.1 \%$. The median OS was not reached during the follow-up time. The lymph node status was a significant prognostic factor for OS (Figure 2, Log rank, $\mathrm{p}=0.001$ ).

Among all T1 tumors from the Registry, 31 (8.8\%) were surgically treated at the Department of Gynecologic Oncology, University Hospital in Pleven. Those are 4.97\% of all FIGO stage I patients treated at our department and $84 \%$ of all diagnosed ASC (in all stages). Among those 31 patients, $20(64.5 \%)$ were with FIGO stage IB1, and 11 $(35.5 \%)$ were with FIGO stage IB2. All have undergone radical hysterectomy with total pelvic lymph node dissection, followed by postoperative radiotherapy.

Characteristics of both patients registered at the National Registry and those treated in our department are given in Table 2.

When we compared the two groups of patients, those in group 2 who were treated at our institution were significantly younger $(\mathrm{p}=0.021)$ with insignificantly lower tumor grade and less involved lymph nodes (Figure 3 ).

Further stratification of the patients in group 1, according to tumor size, menopausal status and lymph nodes is shown in Table 3. This information was not available for patients registered in the National Registry.

More than half of the patients in group 2 are premenopausal $-51.6 \%$ and $32.3 \%$ are postmenopausal. The most common size of the tumor is $<2 \mathrm{~cm}(45.2 \%)$, followed by $>4 \mathrm{~cm}(35.5 \%)$. Positive lymph nodes were detected in $32.2 \%$. The 5 -year observed OS is $74.19 \%$. 


\section{Patients with cancer of the uterine cervix, diagnosed in Bulgaria 2007-2016}

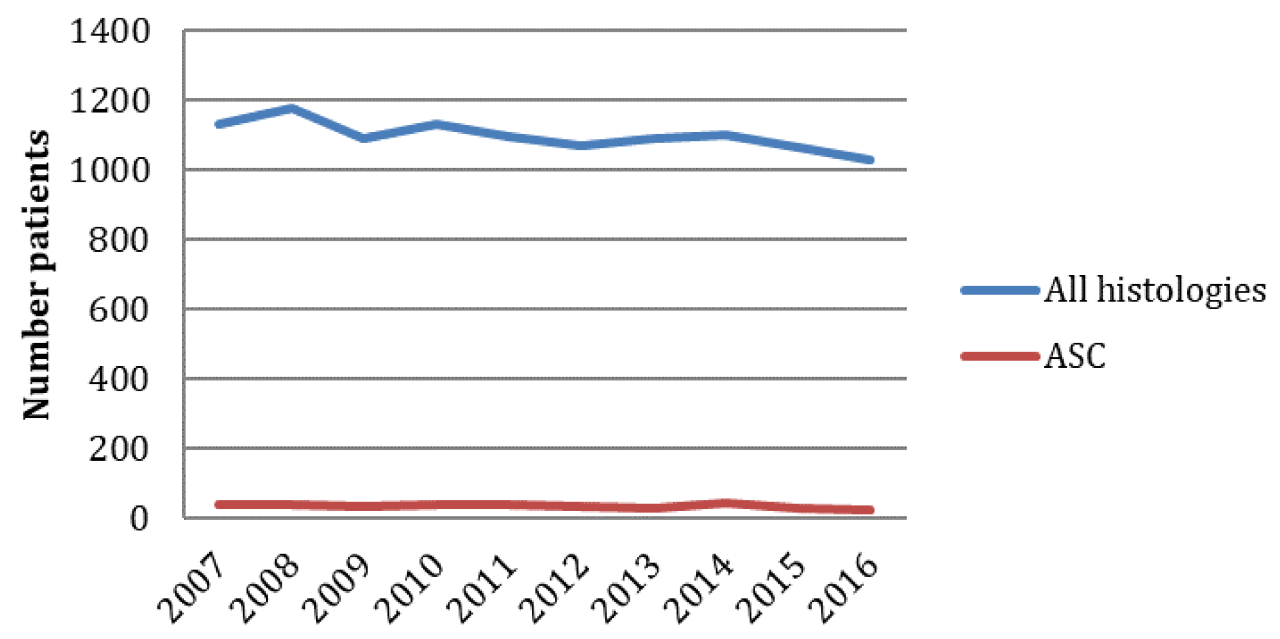

Figure I Distribution of patients, according to the year of diagnosis and the prevalence of patients with ASC.
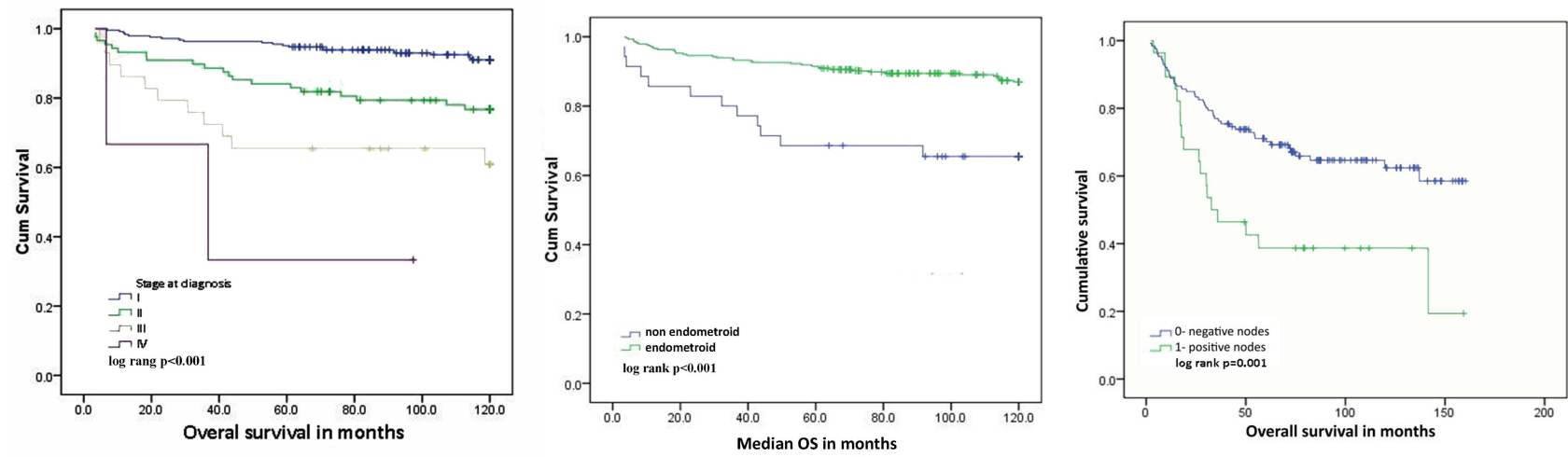

Figure 2 Overall survival according to stage, histologic type and lymph nodes status of all TI patients registered at the Bulgarian National Cancer Registry for the study period.

\section{Discussion}

The incidence of ASC among all patients from the National Cancer Registry is $3.2 \%$ and among patients with $\mathrm{T} 1$ treated at our department is $4.97 \%$. Results are similar and in the range of the previously reported in the literature incidence rates. Diagnosis of ASC of the cervix might be difficult and often patients are reclassified after the first diagnosis. ${ }^{14}$ This may explain the difference in the incidence rate of ASC in our department and at the national level.

The observed 5-year OS of all 353 patients, diagnosed with ASC for the study period, is $50.5 \%$, which is lower than the 5-year survival of all cervical carcinomas from the same period of time in Bulgaria. This gives us even indirect evidence that the prognosis patients with ASC of the uterine cervix is worse compared to the prognosis of patients with other histology. ${ }^{1}$

From all 31 patients surgically treated at the Department of Gynecologic Oncology, University Hospital in Pleven, Bulgaria, $20(64.5 \%)$ were diagnosed with a tumor size $<4 \mathrm{~cm}$, and $14(45.2 \%)$ were with tumors $<2 \mathrm{~cm}$. This evidence supports the concept that screening programs benefit early detection of this carcinoma type, in contrast to AC. Metastatic lymph nodes were found in 10 patients (32.2\%); in $6(60 \%)$ of the cases, tumor size was $>4 \mathrm{~cm}$, and in 2 cases the tumors' size was up to $2 \mathrm{~cm}$ and between 2 and $4 \mathrm{~cm}$, respectively. This is in line with the fact that large tumor size increases the risk of lymphogenous metastasis. Five-year observed OS was estimated at $74.19 \%$, which is a significantly lower rate than previously reported $92 \%$ 
Table 2 Characteristics of Patients with TI ASC, Registered at the Bulgarian National Cancer Register and Patients Treated Department of Gynecologic Oncology, University Hospital in Pleven. (2007-2016)

\begin{tabular}{|l|l|l|}
\hline $\begin{array}{l}\text { Characteristics } \\
\text { of Patients TI }\end{array}$ & $\begin{array}{l}\text { National Cancer } \\
\text { Registry } \\
\text { (Group I) n (\%) }\end{array}$ & $\begin{array}{l}\text { UMHAT “D-r Georgi } \\
\text { Stranski” Pleven } \\
\text { (Group 2) n (\%) }\end{array}$ \\
\hline Age & $51.9(26-88)$ & $48(29-62)$ \\
N0 & $127(74.3 \%)$ & $21(71 \%)$ \\
NI & $25(14.6 \%)$ & $10(22.6 \%)$ \\
Unknown N & $19(11.1 \%)$ & $0(0 \%)$ \\
GI & $2(1.2 \%)$ & $0(0 \%)$ \\
G2 & $69(40.3 \%)$ & $15(48.4 \%)$ \\
G3 & $35(20.5)$ & $4(12.9 \%)$ \\
Unknown G & $65(38 \%)$ & $12(38.7 \%)$ \\
Total & 171 & 31 \\
\hline
\end{tabular}

survival for the first stage. ${ }^{21}$ This is due to the fact that our patients were clinically diagnosed as stage I and subsequently restaged based on the identification of metastatic lymph nodes. Regardless of the small number of patients, we believe that ASC has a worse prognosis than SCC.

Ten $(32.2 \%)$ of the patients from our Department have died during the follow-up time. Six of them have lymphatic metastases. In 4 of these cases, tumor size was $>4 \mathrm{~cm}$. In the group of deceased cases without lymphatic metastases, one case was with a tumor size $>4 \mathrm{~cm}$. From all patients who died during the follow up 7 were with lymphatic metastases and/or tumor size $>4 \mathrm{~cm}$, ie high-risk patients. All patients underwent postoperative radiotherapy. Despite that the survival rate is comparatively low, which makes it suggest that high-risk ASC patients should be treated more aggressively. Performing postoperative radiotherapy could be one of the reasons for the better outcome observed in our patients. The
Table 3 Characteristics of Patients with TI ASC, Treated at the Department of Gynecologic Oncology, University HospitalPleven, Bulgaria (2007-2016)

\begin{tabular}{|l|l|}
\hline Patients' Characteristics & N (\%) \\
\hline Premenopausal & $16(51.6 \%)$ \\
Perimenopausal & $5(16.1 \%)$ \\
Postmenopausal & $10(32.3 \%)$ \\
Size of primary tumor $<2 \mathrm{~cm}, \mathrm{n}(\%)$ & $14(45.2 \%)$ \\
Size of primary tumor 2-4 cm, n (\%) & $6(19.3 \%)$ \\
Size of primary tumor $>4 \mathrm{~cm}, \mathrm{n} \mathrm{( \% )}$ & $11(35.5 \%)$ \\
Positive lymph nodes (N+) & $10(32.2 \%)$ \\
5-year observed survival & $74.19 \%$ \\
Total & 31 \\
\hline
\end{tabular}

information for tumor size in millimeters is not available at the National Cancer Registry database and this could also affect survival differences observed between patients treated in our department and patients treated elsewhere. Clinical behavior of ASC, as demonstrated in our case series, confirms that ASC is to some extent closer to SCC, rather than to $\mathrm{AC}$, but nonetheless has its own specific features, including worse prognosis and higher lymphogenous metastatic potential.

Management in oncology is continuously evolving, with major advances in recent years. In the past, when surgery was the initial and frequently the only treatment modality, initial clinical staging of the disease was used to guide the management of patients. Other treatment modalities were referred to as either adjuvant or neoadjuvant as surgery was considered the only radical modality. In oncology, the biology-driven approach is becoming more recognized and it is incorporated into the clinical strategy initially at diagnosis.

With the development of the technology, the imaging and the radiotherapy, and the introduction of systemic
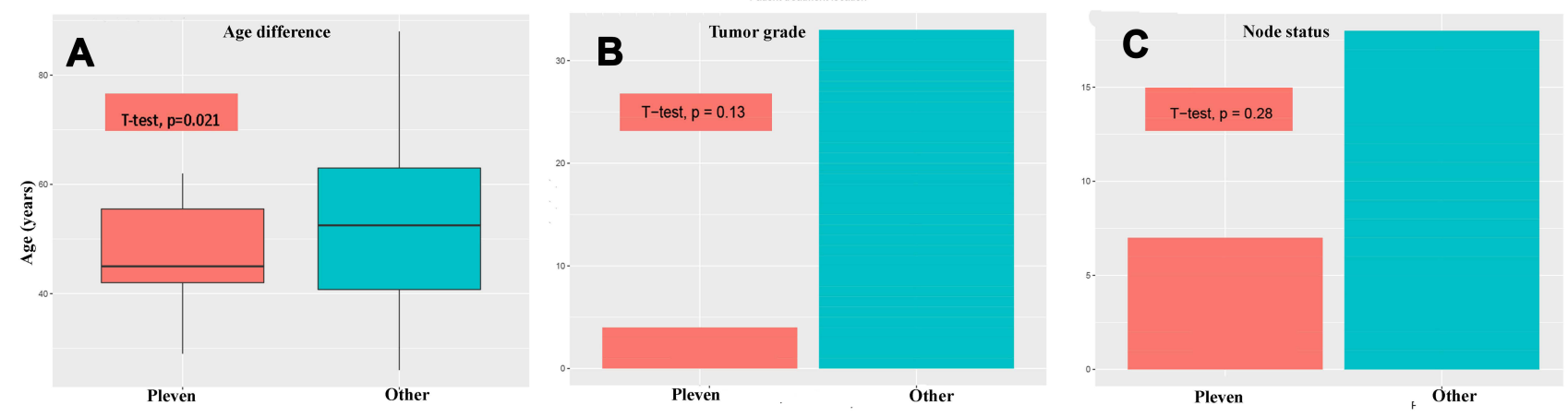

Figure 3 Comparison of patients, treated at UMHAT “D-r Georgi Stranski” Pleven with all other patients treated in Bulgaria for the study period by age (A), tumor grade (B) and lymph node involvement (C). 
treatment (chemo- and targeted therapy), prognosis of cervical cancer patients has improved. It has been established that different pathophysiology has a prognostic significance and thus may become an important factor in selecting patients for escalation or de-escalation of treatment. SCC histology is also a predictive factor of a better response to radiotherapy, ${ }^{22}$ including in the palliative setting. Since AC and SCC have different precursor lesions, ${ }^{23}$ hence their management and response to therapy differ. It is considered that early vaccination against HPV types, associated with higher risk for SCC, may contribute to a significant decrease in morbidity and thus decreased mortality for SCC. ${ }^{24}$ While anti-HPVvaccination and screening programs, especially those including liquid-based cytology and DNA-HPV tests lead to a decline in both morbidity and mortality due to SCC, ${ }^{25}$ the same is not applicable to AC.

Both malignant glandular and squamous differentiation should be present for a tumor to be classified as adenosquamous carcinoma. It should be distinguished from invasive stratified mucin-producing carcinoma, invasive stratified mucin-producing carcinoma with components, and HPVassociated adenocarcinomas with benign-appearing squamous metaplasia. ${ }^{14}$ Until 2014, when WHO introduced criteria for accurate diagnosis of ASC, some of the above tumor types and less distinct subtypes were classified as ASC type. Currently, ASC type group includes glassy cell carcinoma and mucoepidermoid carcinoma. ${ }^{12,26-30}$ Data confirm the monoclonal origin of ASC, differentiating it as a distinct biological entity from both SCC and AC. ${ }^{31}$ Precursors to this carcinoma type are high-grade squamous intraepithelial lesion (HSIL) and adenocarcinoma in situ (ACIS) with frequent detection of Human Papilloma Virus types 16 and 18 related to them. ${ }^{10,32}$ Vaccination is considered to reduce the incidence of ASC due to the presence of these particular HPV types. However, despite the increasing incidence of $\mathrm{AC}$ of the uterine cervix worldwide, the incidence of ASC does not change. ${ }^{6}$ Additional evidence suggesting that ASC is closer to $\mathrm{SCC}$ than to $\mathrm{AC}$, is that the efficacy of cervical cancer screening programs is similar for ASC and SCC and higher than that for AC. ${ }^{33,34}$

Furthermore, there are substantial uncertainties about the survival and prognosis of patients with ASC. Some researchers regard ASC in advanced stages with worse prognosis compared to AC as opposed to its earlier stages. ${ }^{17,35,36}$ Other studies do not show a definite difference in the 5-year survival of ASC, AC, and SCC of the cervix at the same stages and indicate that a worse prognosis is associated with a larger tumor size and metastatic lymph nodes. ${ }^{18,37}$
Lymphovascular space invasion is more likely to occur in patients with ASC, but there is no significant difference in the prognosis between $\mathrm{AC}$ and ASC patients. ${ }^{38}$ In patients, treated with definitive radiotherapy, those with ASC had a worse prognosis than patients with $\mathrm{SCC}^{8}$ but in cases when concurrent chemoradiotherapy was used, the prognosis was similar in both groups. ${ }^{39}$ It is generally suggested that patients with ASC have worse prognosis than patients with SCC. ${ }^{40}$ Yokoi et al found that older age $(>50)$ is an independent prognostic factor for reduced progression-free survival in patients with ASC histology. ${ }^{35}$

\section{Conclusion}

Adenosquamous carcinoma is a rare type of cervical cancer. Screening programs may benefit its early detection. Clinically, it is closer to SCC, rather than AC. Patients with locally advanced carcinomas and/or lymphogenous metastases should undergo more aggressive postoperative treatment as these factors reduce survival.

Currently, histology-driven approach is emerging as a clinical strategy, identifying high-risk patients. Disease stage is guiding the treatment strategy, but tumor biology is an additional important prognostic and potentially predictive factor. Escalation of treatment (eg chemoradiotherapy) may improve the prognosis of patients with poor prognostic features, including adenosquamous histology. The pathophysiology of cervical carcinoma should no longer be a descriptive characteristic but rather be incorporated into the clinical management of patients.

\section{Data Sharing Statement}

Authors declare that all related data are available concerning researchers by the corresponding author's email.

\section{Ethical Disclosures}

Informed consents were signed antemortem by those participating in the study, stating that they knowingly and willingly donate their bodies to medical education and scientific work.

\section{Acknowledgments}

This publication emerged from the European Cooperation in Science \& Technology program (EU COST)-COST Action CA18117:GYNOCARE: "European network for Gynecological Rare Cancer research: From Concept to Cure". A.Y., M.V.-S., R.D.F., J.C.-A. and XXXX are authors. All authors are Action management committee members and/or form part of Working Group 1, and J.C.-A. is the 
Chairperson of this Action. Minka Yordanova, Expert System Software and Database, Bulgarian National Cancer Registry. Nikolai Genov - Leap Dynamics.

\section{Author Contributions}

All authors made substantial contributions to conception and design, acquisition of data, or analysis and interpretation of data; took part in drafting the article or revising it critically for important intellectual content; agreed to submit to the current journal; gave final approval of the version to be published; and agree to be accountable for all aspects of the work Funding: The publication of this manuscript was funded by the European Cooperation in Science \& Technology program (EU COST)-COST Action CA18117: GYNOCARE- "European network for Gynaecological Rare Cancer research: From Concept to Cure".

\section{Disclosure}

The authors declare no competing interests in this work.

\section{References}

1. CONCORD Working Group; Allemani C, Matsuda T, Di Carlo V, et al. Global surveillance of trends in cancer survival 2000-14 (CONCORD-3): analysis of individual records for 37513025 patients diagnosed with one of 18 cancers from 322 population-based registries in 71 countries. Lancet. 2018;391(10125):1023-1075. doi:10.1016/ S0140-6736(17)33326-3.

2. Arbyn M, Weiderpass E, Bruni L, et al. Estimates of incidence and mortality of cervical cancer in 2018: a worldwide analysis. Lancet Glob Health. 2020;8(2):e191-e203. doi:10.1016/S2214-109X(19) 30482-6

3. Bray F, Lortet-Tieulent J, Znaor A, Brotons M, Poljak M, Arbyn M. Patterns and trends in human papillomavirus-related diseases in Central and Eastern Europe and Central Asia. Vaccine. 2013;31 (Suppl 7):H32-H45. doi:10.1016/j.vaccine.2013.02.071

4. International Agency for Reseach on Cancer. Cancer Today. Available from: https://gco.iarc.fr/today/data/factsheets/populations/100-bulgaria -fact-sheets.pdf. Accessed August 01, 2020.

5. Simms KT, Hanley SJB, Smith MA, Keane A, Canfell K. Impact of HPV vaccine hesitancy on cervical cancer in Japan: a modelling study. Lancet Public Health. 2020;5(4):e223-e234. doi:10.1016/S24682667(20)30010-4

6. Castanon A, Landy R, Sasieni PD. Is cervical screening preventing adenocarcinoma and adenosquamous carcinoma of the cervix? Int J Cancer. 2016;139(5):1040-1045. doi:10.1002/ijc.30152

7. Meijer CJLM, Steenbergen RDM. Gynaecological cancer: novel molecular subtypes of cervical cancer - potential clinical consequences. Nat Rev Clin Oncol. 2017;14:397-398. doi:10.1038/ nrclinonc.2017.52

8. Zhou J, Wu SG, Sun JY, et al. Comparison of clinical outcomes of squamous cell carcinoma, adenocarcinoma, and adenosquamous carcinoma of the uterine cervix after definitive radiotherapy: a population-based analysis. J Cancer Res Clin Oncol. 2017;143 (1):115-122. doi:10.1007/s00432-016-2246-9

9. Rarecare.net; 2021. Available from: http://www.rarecare.eu/default. asp. Accessed December 17, 2020.
10. Yoshida T, Sano T, Oyama T, Kanuma T, Fukuda T. Prevalence, viral load, and physical status of HPV 16 and 18 in cervical adenosquamous carcinoma. Virchows Arch. 2009;455(3):253-259. doi:10.1007/ s00428-009-0823-x

11. Perunovic BSA. Adenosquamous carcinoma. PathologyOutlines.com website; 2019. Available from: http://www.pathologyoutlines.com/ topic/cervixadenosquamous.html. Accessed January 12, 2019.

12. Cherry CP, Glucksmann A. Incidence, histology, and response to radiation of mixed carcinomas (adenoacanthomas) of the uterine cervix. Cancer. 1956;9:971-999. doi:10.1002/1097-0142(195609/ 10)9:5<971::AID-CNCR2820090518>3.0.CO;2-T

13. Stoler M, Bergeron C, Colgan TJ, et al. Tumours of the uterine cervix. In: Kurman RJ, Carcangiu ML, Herrington CS, et al. editors. WHO Classification of Tumours of Female Reproductive Organs. 4th. Lyon, France: IARC Press; 2014:184.

14. Stolnicu S, Hoang L, Hanko-Bauer O, et al. Cervical adenosquamous carcinoma: detailed analysis of morphology, immunohistochemical profile, and clinical outcomes in 59 cases. Mod Pathol. 2019;32 (2):269-279. doi:10.1038/s41379-018-0123-6

15. Wells M, Ostor AG, Crum CP, et al. Tumours of the uterine cervix. In: Tavassoli FA, Deville P, editors. Tumours of the Breast and Female Genital Organcs. Lyon, France: IARC Press; 2003:277.

16. Guitarte C, Alagkiozidis I, Mize B, Stevens E, Salame G, Lee YC. Glassy cell carcinoma of the cervix: a systematic review and meta-analysis. Gynecol Oncol. 2014;133(2):186-191. doi:10.1016/j. ygyno.2014.01.048

17. Farley JH, Hickey KW, Carlson JW, Rose GS, Kost ER, Harrison TA. Adenosquamous histology predicts a poor outcome for patients with advanced-stage, but not early-stage, cervical carcinoma. Cancer. 2003;97:2196-2202. doi:10.1002/cncr.11371

18. Shingleton HM, Bell MC, Fremgen A, et al. Is there really a difference in survival of women with squamous cell carcinoma, adenocarcinoma, and adenosquamous cell carcinoma of the cervix? Cancer. 1995;76:1948-1955.

19. Noh JM, Park W, Kim YS, et al. Comparison of clinical outcomes of adenocarcinoma and adenosquamous carcinoma in uterine cervical cancer patients receiving surgical resection followed by radiotherapy: a multicenter retrospective study (KROG 13-10). Gynecol Oncol. 2014;132(3):618-623. doi:10.1016/j.ygyno.2014.01.043

20. Huang YT, Wang CC, Tsai CS, et al. Long-term outcome and prognostic factors for adenocarcinoma/adenosquamous carcinoma of cervix after definitive radiotherapy. Int $J$ Radiat Oncol Biol Phys. 2011;80(2):429-436. doi:10.1016/j.ijrobp.2010.02.009

21. American Cancer Society. Survival Rates for Cervical Cancer. Available from: www.cancer.org/cancer/cervical-cancer/detectiondiagnosis-staging/survival.html. Accessed August 01, 2020.

22. Hu K, Wang W, Liu X, Meng Q, Zhang F. Comparison of treatment outcomes between squamous cell carcinoma and adenocarcinoma of cervix after definitive radiotherapy or concurrent chemoradiotherapy. Radiat Oncol. 2018;13(1):249. doi:10.1186/s13014-018-1197-5

23. Lax S. Histopathology of cervical precursor lesions and cancer. Acta Dermatovenerol Alp Pannonica Adriat. 2011;20(3):125-133.

24. Pimenta JM, Galindo C, Jenkins D, Taylor SM. Estimate of the global burden of cervical adenocarcinoma and potential impact of prophylactic human papillomavirus vaccination. BMC Cancer. 2013;13:553. doi:10.1186/1471-2407-13-553

25. Lewitowicz P, Nasierowska-Guttmejer A, Rokita W, et al. HPV genotyping and p16/Ki-67 test significantly improve detection rate of high-grade cervical squamous intraepithelial lesion. Arch Med Sci. 2019;16(1):87-93. doi:10.5114/aoms.2018.80697

26. Green LS, Muirhead W. Improvement in results of treatment of carcinoma of the cervix. J Can Assoc Radiol. 1963;14:191-199.

27. Costa MJ, Kenny MB, Hewan-Lowe K, Judd R. Glassy cell features in adenosquamous carcinoma of the uterine cervix. Histologic, ultrastructural, immunohistochemical, and clinical findings. Am J Clin Pathol. 1991;96:520-528. doi:10.1093/ajcp/96.4.520 
28. Zhang X, Lv Z, Xu X, Yin Z, Lou H. Comparison of adenocarcinoma and adenosquamous carcinoma prognoses in Chinese patients with FIGO stage IB-IIA cervical cancer following radical surgery. $B M C$ Cancer. 2020;20(1):664. doi:10.1186/s12885-020-07148-x

29. Lennerz JK, Perry A, Mills JC, Huettner PC, Pfeifer JD. Mucoepidermoid carcinoma of the cervix: another tumor with the $\mathrm{t}$ (11;19)-associated CRTC1-MAML2 gene fusion. Am J Surg Pathol. 2009;33:835-843. doi:10.1097/PAS.0b013e318190cf5b

30. McCluggage WG. New developments in endocervical glandular lesions. Histopathology. 2013;62:138-160. doi:10.1111/his.12012

31. Ueda Y, Miyatake T, Okazawa M, et al. Clonality and HPV infection analysis of concurrent glandular and squamous lesions and adenosquamous carcinomas of the uterine cervix. Am J Clin Pathol. 2008;130:389e400. doi:10.1309/ERR93AF840YYNDRQ

32. Andersson S, Rylander E, Larsson B, Strand A, Silfversvard C, Wilander E. The role of human papillomavirus in cervical adenocarcinoma carcinogenesis. Eur J Cancer. 2001;37:246e50. doi:10.1016/ S0959-8049(00)00376-2

33. Sasieni P, Castanon A, Cuzick J. Screening and adenocarcinoma of the cervix. Int $J$ Cancer. 2009;125:525-529. doi:10.1002/ ijc. 24410

34. Andrae B, Kemetli L, Sparén P, et al. Screening-preventable cervical cancer risks: evidence from a nationwide audit in Sweden. J Natl Cancer Inst. 2008;100:622-629. doi:10.1093/jnci/djn099

35. Yokoi E, Mabuchi S, Takahashi R, et al. Impact of histological subtype on survival in patients with locally advanced cervical cancer that were treated with definitive radiotherapy: adenocarcinoma/adenosquamous carcinoma versus squamous cell carcinoma. J Gynecol Oncol. 2017;28(2):e19. doi:10.3802/jgo.2017.28.e19
36. Lee J, Lee C, Hahn S, et al. Prognosis of adenosquamous carcinoma compared with adenocarcinoma in uterine cervical cancer: a systematic review and meta-analysis of observational studies. Int J Gynecolog Cancer. 2014;24:289-294. doi:10.1097/IGC.0000000000000063

37. Kawakami Y, Takehara K, Kumagai M, et al. A retrospective review of adenosquamous carcinoma of the uterine cervix. J Clin Oncol. 2007;25(18_suppl):16049. doi:10.1200/jco.2007.25.18_suppl.16049

38. Chen Q, Liu L, Zhang J, et al. Clinical features and prognosis of cervical adenocarcinoma and adenosquamous carcinoma: an analysis of 237 cases. Zhejiang Da Xue Xue Bao Yi Xue Ban. 2018;47 (4):357-361. Article in Chinese.

39. Rose PG, Java JJ, Whitney CW, Stehman FB, Lanciano R, Thomas GM. Locally advanced adenocarcinoma and adenosquamous carcinomas of the cervix compared to squamous cell carcinomas of the cervix in gynecologic oncology group trials of cisplatin-based chemoradiation. Gynecol Oncol. 2014;135:208-212. doi:10.1016/j. ygyno.2014.08.018

40. Mabuchi S, Okazawa M, Kinose Y, et al. Comparison of the prognoses of FIGO stage I to stage II adenosquamous carcinoma and adenocarcinoma of the uterine cervix treated with radical hysterectomy. Int $J$ Gynecol Cancer. 2012;22:1389-1397. doi:10.1097/IGC.0b013e31826b5d9b

\section{Publish your work in this journal}

Cancer Management and Research is an international, peer-reviewed open access journal focusing on cancer research and the optimal use of preventative and integrated treatment interventions to achieve improved outcomes, enhanced survival and quality of life for the cancer patient.
The manuscript management system is completely online and includes a very quick and fair peer-review system, which is all easy to use. Visit http://www.dovepress.com/testimonials.php to read real quotes from published authors. 